\title{
Cement leakage in pedicle screw augmentation: a prospective analysis of 98 patients and 474 augmented pedicle screws
}

\author{
Jan U. Mueller, MD, ${ }^{1}$ Joerg Baldauf, MD, ${ }^{1}$ Sascha Marx, MD, ${ }^{1}$ Michael Kirsch, MD, ${ }^{2}$ \\ Henry W. S. Schroeder, MD, PhD, ${ }^{1}$ and Dirk T. Pillich, MD ${ }^{1}$ \\ 'Department of Neurosurgery, University Medicine Greifswald, ${ }^{2}$ Department of Radiology and Neuroradiology, \\ University Medicine Greifswald, Germany
}

OBJECTIVE Loosening and pull-out of pedicle screws are well-known problems in pedicle screw fixation surgery. Augmentation of pedicle screws with bone cement, first described as early as 1975 , increases the pedicle-screw interface and pullout force in osteoporotic vertebrae. The aim of the present study was to identify cement leakage and pulmonary embolism rates in a large prospective single-center series of pedicle screw augmentations.

METHODS All patients who underwent cement-augmented pedicle screw placement between May 2006 and October 2010 at the authors' institution were included in this prospective cohort study. Perivertebral cement leakage and pulmonary cement embolism were evaluated with a CT scan of the area of operation and with a radiograph of the chest, respectively.

RESULTS A total of 98 patients underwent placement of cement-augmented pedicle screws; 474 augmented screws were inserted in 237 vertebrae. No symptomatic perivertebral cement leakage or symptomatic pulmonary cement embolism was observed, but asymptomatic perivertebral cement leakage was seen in 88 patients (93.6\%) and in 165 augmented vertebrae $(73.3 \%)$. Cement leakage most often occurred in the perivertebral venous system. Clinically asymptomatic pulmonary cement embolism was found in 4 patients (4.1\%).

CONCLUSIONS Perivertebral cement leakage often occurs in pedicle screw augmentation, but in most cases, it is clinically asymptomatic. Cement augmentation should be performed under continuous fluoroscopy to avoid high-volume leakage. Alternative strategies, such as use of expandable screws, should be examined in more detail for patients at high risk of screw loosening.

http://thejns.org/doi/abs/10.3171/2015.10.SPINE15511

KEY WORDS pedicle screw; cement augmentation; cement leakage; technique

$\gamma^{1}$ INCE the introduction of pedicle screw fixation in spine surgery, loosening and pull-out of pedicle screws have become well-known problems. In many patients, especially those with osteoporosis, pedicle screw anchoring may be problematic, ${ }^{23,55}$ and several efforts to cope with this challenge have failed. Increasing screw length and diameter leads to an improved screw-bone interface in nonosteoporotic vertebrae but not in osteoporotic vertebrae, ${ }^{6}$ and increased screw diameter, in particular, increases the risk of pedicle rupture. ${ }^{23}$ Bicortical anchoring leads to enhanced pullout force but may also increase the risk of vascular or visceral injuries. ${ }^{2}$
Augmentation of pedicle screws with bone cement was described as early as 1975 and increases the pediclescrew interface and pullout strength in osteoporotic vertebrae. ${ }^{8,19,42,43}$ It allows pedicle screw fixation in patients with preoperatively known risk for screw loosening. Various types of cement and techniques of application have been described ${ }^{42}$ but all of them involve the risk of cement leakage into the venous system or along fracture gaps around the vertebrae. Cement leakage rates are reported in the literature of $13 \%$ to $17 \% .^{3,10,25,31,35}$ Indeed, pulmonary cement embolism may occur. ${ }^{1}$

The aim of the present study was to identify cement

ABBREVIATIONS ASIA = American Spinal Injury Association; PMMA = polymethylmethacrylate; $\mathrm{VAS}=$ visual analog scale .

SUBMITTED May 4, 2015. ACCEPTED October 30, 2015.

INCLUDE WHEN CITING Published online March 4, 2016; DOI: 10.3171/2015.10.SPINE15511. 
leakage and pulmonary embolism rates in a large prospective monocentric series of pedicle screw augmentations. We hypothesize that the actual leakage rate is higher than the rates that have been reported in the literature.

\section{Methods}

All patients treated with augmented pedicle screws between May 2006 and October 2010 were included in the present prospective study. Perivertebral cement leakage was evaluated with a CT scan of the area of operation performed within 72 hours postoperatively and was categorized according to the classification of Yeom et al..$^{54}$ Their study clearly pointed out the superiority of a CT scan compared with a radiograph to evaluate cement leakage after vertebroplasty. Yeom and coauthors demonstrated that use of only anteroposterior and lateral radiographs failed to identify the whole amount of cement leakage related to the spinal canal or neural foramina, respectively. The evaluation for pulmonary cement embolism was done with an anterior-posterior radiograph of the chest obtained within 24 hours postoperatively. Even if the patients did not complain of pulmonary problems, cement distribution to the thorax was assessed. All radiological reports were done by an experienced radiologist (K.M.). Additionally, perioperative data were recorded, including the number of vertebrae treated, operative complications, blood loss, and duration of the operation (from incision to closure). Perioperative pain was evaluated with a visual analog scale. ${ }^{15}$ Neurological deficits were classified with the American Spinal Injury Association (ASIA) Impairment Scale. Results are given in absolute numbers and percentages. The study was approved by the local ethics committee.

\section{Operative Technique}

All operations were performed under general anesthesia. Patients were in a prone position on a carbon plate due to the need for an intraoperative 3D scan (Siremobil ISO-C ${ }^{3 \mathrm{D}}$, Siemens AG, Medical Solutions). All procedures were performed using pedicle screws from the Tango System (Ulrich GmbH \& Co. KG) and polymethylmethacrylate (PMMA) cement. The screw is fully cannulated with 20 radial holes (hole diameter $1.2 \mathrm{~mm}$ ) and an inner diameter of $1.68 \mathrm{~mm}$. The radial holes are all within the distal third of the screw. Screw placement was performed according to the technique described by Weinstein et al. ${ }^{51}$ The decision for augmentation was made by an experienced surgeon after screw placement according to the mechanical strength of the implanted pedicle screw. After evaluation of correct screw position with the 3D scan and, if required, screw revision, the cement application system was fixed on top of the screw. Under intermittent X-ray fluoroscopy $1.5 \mathrm{ml}$ or $2 \mathrm{ml}$ PMMA per pedicle screw was administered in the thoracic or lumbar spine, respectively. Injection was interrupted if cement leakage was observed. The procedure was continued after curing of the PMMA. PMMA preparation and application was done according to the instructions given by the company. Therefore, the phase duration of mixing powder and liquid was $30 \mathrm{sec}-$ onds, application device filling was also 30 seconds, and the waiting period of 300 seconds had to be maintained before use of the cement.

Four experienced spine surgeons performed the operations. The technique does not require a steep learning curve.

\section{Results \\ Cement Leakage and Pulmonary Embolism Rate}

In the study period, pedicle screw augmentation was performed in 98 patients. A total of 474 augmented screws were inserted in 237 vertebrae. For the evaluation of cement leakage rates, 4 patients $(4.1 \%), 8$ vertebrae (3.4\%), and 16 screws (3.4\%) had to be excluded due to missing postoperative CT scans. For the evaluation of pulmonary embolism, all patients were eligible. No symptomatic perivertebral cement leakage or a symptomatic pulmonary cement embolism was observed. However, asymptomatic perivertebral cement leakage was seen in 88 patients (93.6\%) and in 165 augmented vertebrae (73.3\%). With respect to the classification of perivertebral cement leakage according to Yeom at al. ${ }^{54}$ leakage was seen through the segmental veins, basivertebral vein, and fracture gaps in the vertebral body in 139 (61.8\%), 93 (41.3\%), and 26 $(11.6 \%)$ of vertebrae, respectively (Table 1). Leakage from a single site was seen in 85 vertebrae (37.8\%), and a combination of 2 or 3 leakage sites per vertebra was seen in $75(33.3 \%)$ and 5 (2.2\%) vertebral bodies, respectively. No influence of the underlying pathology on the cement leakage rate was observed. Clinically asymptomatic pulmonary cement embolism was found in 4 patients $(4.1 \%)-1$ with an osteoporotic fracture, 1 with degenerative instability and 2 with pathological fractures (Table 1). No pulmonary embolism or perivertebral cement leakage required further treatment. Representative images demonstrating perivertebral cement leakage and pulmonary cement embolism are shown (Figs. 1 and 2).

\section{Patient Characteristics}

The indications for pedicle screw augmentation were

TABLE 1. Route of cement leakage in numbers per vertebra and number of patients with lung embolism according to the different indications for cement-augmented pedicle screw fixation

\begin{tabular}{ccccc}
\hline & \multicolumn{4}{c}{ Indication } \\
\cline { 2 - 5 } Cement Leakage or Embolism & Osteoporotic Fracture & Pathological Fracture & Degenerative Instability & Total \\
\hline Segmental vein & 31 & 9 & 7 & 47 \\
\hline Basivertebral vein & 42 & 14 & 4 & 60 \\
\hline Fracture gap & 23 & 6 & 6 & 35 \\
\hline Lung embolism & 1 & 2 & 1 & 4 \\
\hline
\end{tabular}



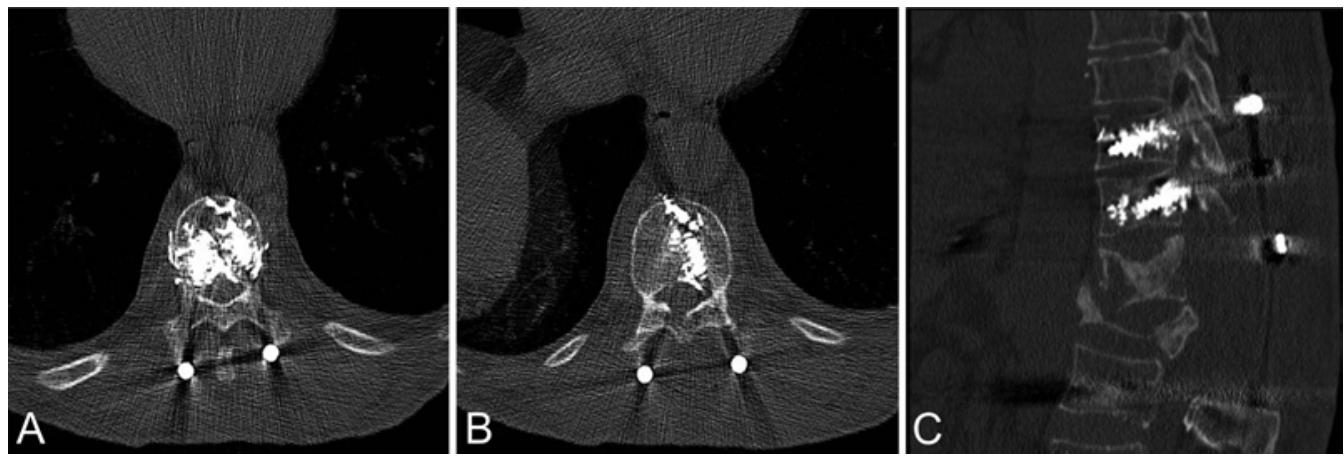

FIG. 1. Postoperative CT scans illustrating leakage types according to the classification of Yeom. A: Type B, on the right side near the neuroforamen, and Type S, a horizontal course in the spinal canal in the epidural plexus. B: Type C, via a cortical defect, and Type S, via a basivertebral vein on the left side in the spinal canal in the epidural plexus. C: Type S, via a basivertebral vein in the epidural plexus.

unstable osteoporotic fractures in 68 patients $(69.4 \%)$, pathological fractures due to bone metastases in $18(18.4 \%)$, and degenerative instability in $12(12.2 \%)$. The patient group included 64 men and 34 women, and the mean age at surgery was 70.6 years (range $41-84$ years). Patients with osteoporotic fractures were older (mean age 72 years) than patients with pathological fractures (mean age 64 years). Augmented pedicle screws were inserted from T-2 to S-1 with the most frequent levels being in the lumbar spine and at the thoracolumbar junction (Fig. 3). Fixation was performed at more levels in patients with pathological fractures than in patients with osteoporotic fractures or degenerative instabilities. The operation was a primary surgery in 83 cases (84.6\%) and a revision surgery in 15 (15.4\%). Operative stabilization with augmented pedicle screws was the only procedure in 55 patients $(56.1 \%)$. Secondary procedures were microsurgical decompression (performed in 26 cases [26.5\%]) and intervertebral body fusion/vertebral

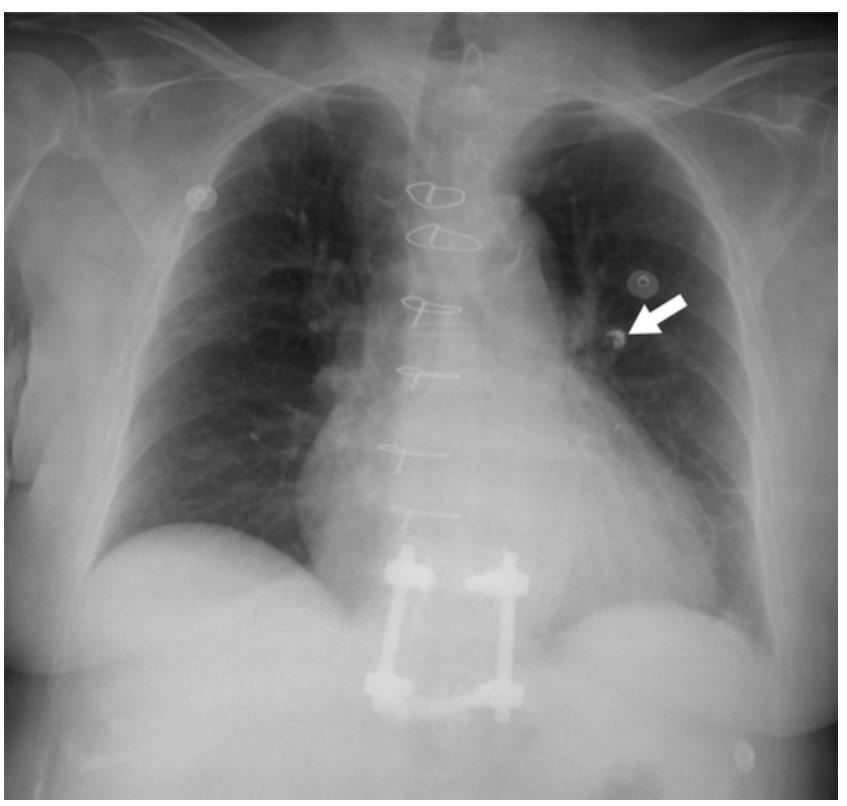

FIG. 2. Anteroposterior radiograph demonstrating a pulmonary cement embolism on the left side (arrow). body reconstruction (performed in 17 cases [17.4\%]). There was no deterioration in the ASIA motor score in any patient, and an improvement of 1 or 2 levels was seen in 10 $(10.2 \%)$ and $1(1 \%)$ of the patients, respectively. The mean visual analog scale (VAS) score improved from 7.4 points at admission to 3.4 points at discharge. Detailed patient characteristics are shown in Table 2.

\section{Perioperative Complications}

No clinical complication due to uncontrolled cement leakage in the spinal canal or cement-induced pulmonary embolism was observed. In 5 patients (5.1\%), cement application was stopped before the target volume was reached due to obvious cement leakage under fluoroscopy control. Intraoperative screw revision due to medial or lateral pedicle perforation occurred in 17 patients (17.3\%) and 19 screws (4\%), respectively. In 3 patients (3.1\%), intraoperative CSF leakage due to screw-related dura mater injury was observed; in all 3 cases, the defect was repaired with allogenic plastic reconstruction. In 2 patients (2\%), a cement-related blockade of the screw locking mechanism occurred. However, the screws were replaced with screws of the same caliber without problems. Major bleeding with more than $1000 \mathrm{ml}$ blood loss was observed in 9 patients (9.2\%), of whom 7 patients had pathological fractures, 1 patient had an osteoporotic fracture, and 1 patient was undergoing multilevel instrumentation placement. In the postoperative course, 2 patients (2\%) suffered from aseptic epifascial seroma. Secondary wound closure could be achieved after repetitive taps and treatment with continuous vacuum therapy.

\section{Discussion}

\section{Summary of Key Results}

The present series of PMMA-augmented pedicle screw placement in 98 patients reveals perivertebral cement leakage in $73.3 \%$ of analyzed vertebral bodies and asymptomatic pulmonary embolism in $4 \%$ of evaluated patients. Cement leakage most often occurred in the perivertebral venous system, including the epidural veins via basivertebral vein. However, no deterioration was seen in the postoperative ASIA impairment scale scores, and no operative cement removal was required. 


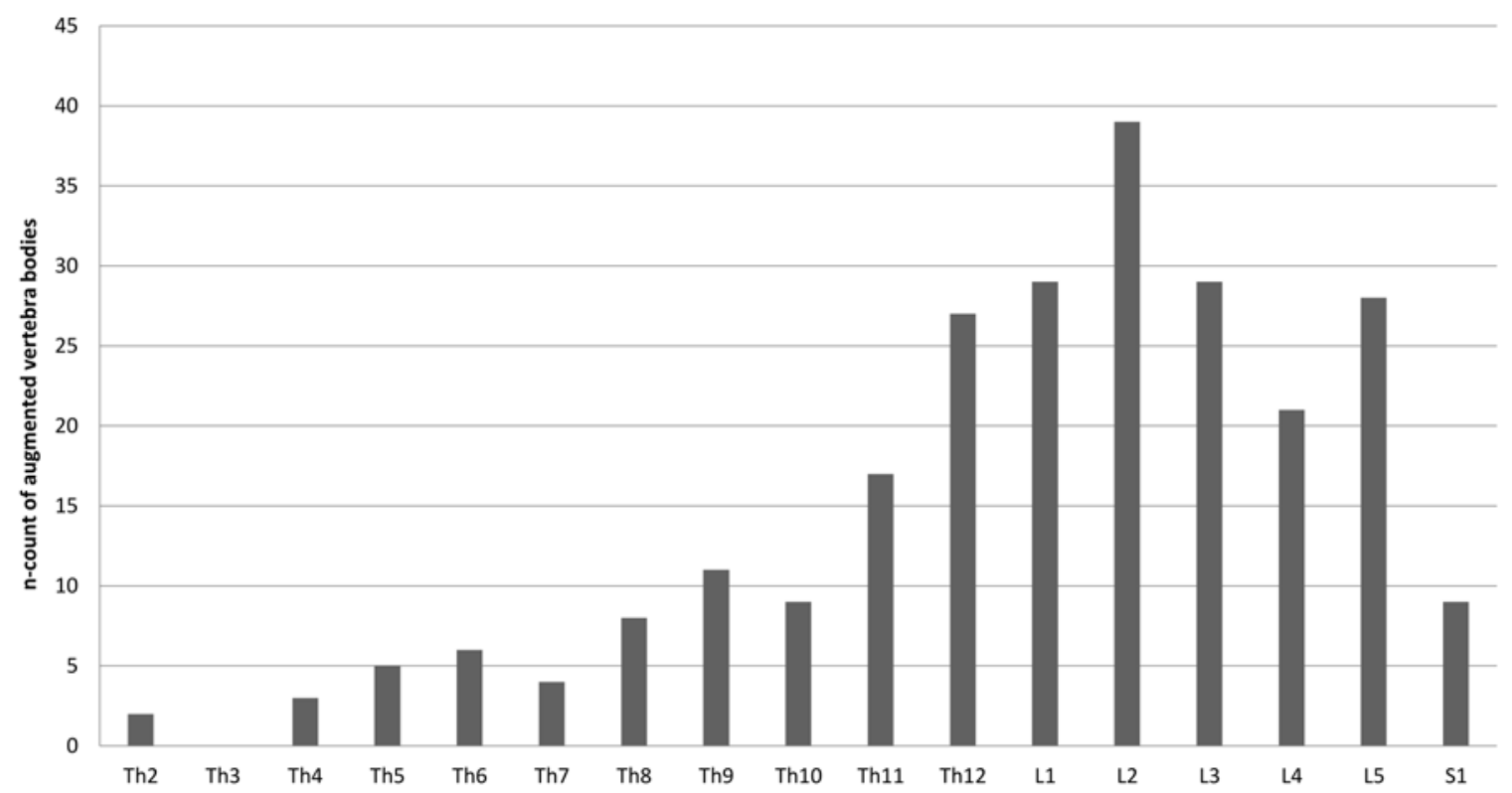

FIG. 3. Frequency of pedicle screw fixation according to vertebral level. Results are given in absolute numbers of all treated vertebral bodies. $\mathrm{Th}=$ thoracic.

\section{Limitations}

Although the present study reveals solid data in a prospective design, some limitations need to be addressed. First, the herein-investigated cement augmentation via cannulated screws is not the only pedicle screw augmentation technique. Cement can be applied in vertebroplasty or kyphoplasty prior to screw insertion, ${ }^{4,27}$ but in these instances, it is applied with less application pressure, and the results of the present study should not be used for extrapolation. Second, there are numerous different pedicle screw types, varying in core diameter and size and number and location of radial holes. ${ }^{42}$ The screw used in the present study has about 20 radial holes in its distal third (hole diameter $1.2 \mathrm{~mm}$ ) and has a core diameter of $1.68 \mathrm{~mm}$. High cement application pressure as well as low cement viscosity are directly related to an increased cement leakage rate. ${ }^{27}$ According to the law of Hagen-Poiseuille, lower application pressure and applicability of cement with a higher viscosity could be achieved by enlargement of both radial holes and core diameter. Additionally, cement leakage occurs most frequently in the most proximal radial holes. ${ }^{12}$ Screw design, therefore, might have an impact on cement leakage rates, and results of the present study cannot be extrapolated to all screw designs. However, previous studies ${ }^{12,31}$ with rates of cement leakage varying between $13 \%$ and $17 \%$ were based on the use of different

TABLE 2. Demographic, operation-related, and clinical outcome data

\begin{tabular}{|c|c|c|c|c|}
\hline \multirow[b]{2}{*}{ Variable } & \multicolumn{4}{|c|}{ Indication } \\
\hline & Osteoporotic Fracture & Pathological Fracture & Degenerative Instability & Total \\
\hline Mean age (yrs) & 72 & 64.4 & 70.4 & 70.6 \\
\hline \multicolumn{5}{|l|}{ Sex (no. of patients) } \\
\hline Female & 47 & 10 & 9 & 60 \\
\hline Male & 21 & 8 & 3 & 38 \\
\hline Mean duration of op (mins) & 158 & 192 & 224 & 174 \\
\hline Mean blood loss (ml) & 324 & 1085 & 535 & 521 \\
\hline \multicolumn{5}{|c|}{$\begin{array}{l}\text { Change in ASIA score from preop to postop } \\
\text { (no. of patients) }\end{array}$} \\
\hline Increased & 6 & 4 & 1 & 11 \\
\hline Unchanged & 52 & 14 & 11 & 77 \\
\hline Decreased & 0 & 0 & 0 & 0 \\
\hline \multicolumn{5}{|l|}{ VAS score, mean } \\
\hline Preop & 7.3 & 7.5 & 7.4 & 7.4 \\
\hline Postop & 3.2 & 3.8 & 3.2 & 3.4 \\
\hline No. of augmented screws per patient & 4.6 & 5.8 & 4.8 & 5 \\
\hline
\end{tabular}


cannulated screws with fewer distal fenestrations than the screws used in our study. Third, the pulmonary embolism rate of $4 \%$ in the present series might be an underestimate due to the low sensitivity of radiographs for detecting it. ${ }^{41}$ However, there is no indication for CT scans of the lung in asymptomatic patients.

\section{Cement Leakage in Pedicle Screw Augmentation is an Underestimated Problem}

Cement leakage during pedicle screw augmentation is a well-known problem. However, reported leakage rates of $0 \%,{ }^{3} 5.4 \%{ }^{35}$ or $14 \%{ }^{10}$ differ greatly from our results. Unfortunately, published data on leakage rates in pedicle screw augmentation with a study group of a size similar to ours are rare. The cement application, however, is comparable to its use in vertebroplasty and kyphoplasty, ${ }^{49}$ and leakage rates might be comparable too. Cement leakage rates in vertebroplasty and kyphoplasty are reported to be between $19.3 \%{ }^{47}$ and $80 \%,{ }^{46}$ but they are usually above $40 \% .^{9,22,24,32,36,44,48,49}$ The reason for high leakage rates in cadaver models might be the missing venous counter-pressure ${ }^{6}$ but this does not explain high leakage rates during surgery. The amount of applied cement in the literature varies between $1.8 \mathrm{ml}$ and $2.9 \mathrm{ml}$ per screw, ${ }^{18,35}$ which is comparable to the amount used in the present study. Biomechanical capacity would not increase after raising the application above $2.8 \mathrm{ml}$ per screw. ${ }^{19}$ Furthermore, there is a positive correlation between the applied cement volume and the likelihood of cement leakage. ${ }^{2,45}$ The cement volume should be kept to the smallest volume needed and should not exceed $2.8 \mathrm{ml}$ per pedicle screw. ${ }^{17} \mathrm{High}$ application pressure, liquidity of the cement, and special anatomical features of the perivertebral venous system are conducive to cement leakage.

\section{The Perivertebral Venous System Fosters Cement Leakage}

Leakage reported in the present study occurred mostly via segmental veins and basivertebral veins, which is in agreement with data from the literature. ${ }^{11}$ Most cement leakage during pedicle screw augmentation is along the perivertebral venous system. ${ }^{11,19,54}$ The reduced pressure of the venous system compared with the pressure of the spongiosa that it surrounds and missing venous valves in the internal and external anterior venous plexus are a reasonable explanation. ${ }^{21}$ The position of the cement in the vertebral body might have a major impact on the leakage rate, since Kaso et al. demonstrated an enhanced cement leakage in the spinal canal via basivertebral vein in a medial needle position under vertebroplasty compared with a lateral position. ${ }^{28}$ With respect to these data, a lateral screw positioning could prevent dangerous cement leakage in the spinal canal. This technique, however, first described by Roy-Camille et al., ${ }^{40}$ leads to an enhanced violation rate of the upper facet joints compared with the method of Weinstein et al., which is used in our department. $14,51,52$

\section{Symptomatic Leakage is Rare}

Cement leakage may cause neurological deficits in sin- gle cases. ${ }^{26}$ However, in the present series there was none of the symptomatic cement leakage reported in other studies. ${ }^{11,19,25,46}$ The rate of cement-associated lung embolism was $4 \%$ in the present study. However, as in most cases, it was clinically asymptomatic. ${ }^{1,29,38,39}$ Due to the low sensitivity of conventional chest radiographs compared with CT scans, a much higher asymptomatic embolism rate must be assumed. ${ }^{30}$ Studies of the rate of pulmonary embolism after percutaneous vertebroplasty have reported substantially different rates depending on the detection modality, with radiographs yielding a rate of $6.8 \% 16$ and CT yielding a rate of $23 \% .^{13}$ Treatment of pulmonary cement embolism is recommended in symptomatic but not asymptomatic cases. The treatment algorithm should follow the guidelines for treatment of thrombotic pulmonary embolism. ${ }^{33}$ Revision of cement-augmented pedicle screws can be done without hesitation, since it was practicable in the present study as well as in reports from the literature.,

\section{Has the Last Word Been Said in Cement Augmentation?}

Cement leakage occurs frequently in pedicle screw augmentation, but it is clinically asymptomatic in most cases. Nevertheless, it is questionable to continue with a basically harmful procedure without making attempts at improvement. For instance, the indications for cement augmentation might be made more objective. Intraoperative, pre-augmentation measurement of bone density could be useful. ${ }^{37}$ Intraoperative osseous phlebography after screw insertion and prior to cement augmentation might be helpful to avoid cement leakage in larger vertebral veins $;{ }^{2}$ however, phlebography is itself associated with risks, including the risk of pedicle rupture, in addition to increasing the overall duration of the operation. Careful injection of cement under continuous fluoroscopy and using the proper amount of cement might be more beneficial. New screw designs involving a cannulated screw with radial holes but a closed tip may reduce anterior leakage, ${ }^{20}$ but anterior leakage does not play a major role. One major problem associated with PMMA is injury to neural tissue. In addition to direct injury due to mechanical irritation, thermal injury can result from the exothermic polymerization process. For this reason cements have been developed that do not generate heat during the hardening process. ${ }^{50}$ Bicortical anchoring of pedicle screws enhances the pullout strength in the same fashion as cement augmentation while increasing the risk of vascular or visceral injuries. ${ }^{2}$ However, risk for vascular injuries might be minimal in the sacral region. Therefore, cement augmentation in the thoracic and lumbar spine and bicortical screw anchoring without augmentation in the sacral spine might be a possible strategy. ${ }^{10}$ Encouraging results are reported for the use of expandable pedicle screws, which have the same biomechanical properties in osteoporotic bone without the risk of cement leakage..$^{13,34,53}$

\section{Conclusions}

Perivertebral cement leakage often occurs in pedicle screw augmentation (73.3\%) but is usually clinically asymptomatic. Cement augmentation should be performed under continuous fluoroscopy to avoid high-volume leak- 
age. The indication for augmentation should be defined with consideration of risks and benefits for the patient. Alternative strategies such as expandable screws should be examined in more detail in patients at high risk for screw loosening. Standard postoperative CT scans of the operation site or the chest may be avoided as long as there is no symptomatic complication. In this way, radiation burden and costs can be lowered.

\section{References}

1. Akinola B, Lutchman L, Barker P, Rai A: Pulmonary cement embolism during cement augmentation of pedicle screw fixation: a case report. J Orthop Surg (Hong Kong) 18:364366,2010

2. Amendola L, Gasbarrini A, Fosco M, Simoes CE, Terzi S, De Iure F, et al: Fenestrated pedicle screws for cement-augmented purchase in patients with bone softening: a review of 21 cases. J Orthop Traumatol 12:193-199, 2011

3. Aydogan M, Ozturk C, Karatoprak O, Tezer M, Aksu N, Hamzaoglu A: The pedicle screw fixation with vertebroplasty augmentation in the surgical treatment of the severe osteoporotic spines. J Spinal Disord Tech 22:444-447, 2009

4. Becker S, Chavanne A, Spitaler R, Kropik K, Aigner N, Ogon M, et al: Assessment of different screw augmentation techniques and screw designs in osteoporotic spines. Eur Spine J 17:1462-1469, 2008

5. Blattert TR, Glasmacher S, Riesner HJ, Josten C: Revision characteristics of cement-augmented, cannulated-fenestrated pedicle screws in the osteoporotic vertebral body: a biomechanical in vitro investigation. Technical note. J Neurosurg Spine 11:23-27, 2009

6. Bullmann V, Liljenqvist UR, Rödl R, Schulte TL: [Pedicle screw augmentation from a biomechanical perspective.] Orthopade 39:673-678, 2010 (Ger)

7. Bullmann V, Schmoelz W, Richter M, Grathwohl C, Schulte TL: Revision of cannulated and perforated cement-augmented pedicle screws: a biomechanical study in human cadavers. Spine (Phila Pa 1976) 35:E932-E939, 2010

8. Cameron HU, Jacob R, Macnab I, Pilliar RM: Use of polymethylmethacrylate to enhance screw fixation in bone. $\mathbf{J}$ Bone Joint Surg Am 57:655-656, 1975

9. Caudana R, Renzi Brivio L, Ventura L, Aitini E, Rozzanigo U, Barai G: CT-guided percutaneous vertebroplasty: personal experience in the treatment of osteoporotic fractures and dorsolumbar metastases. Radiol Med (Torino) 113:114-133, 2008

10. Chang MC, Kao HC, Ying SH, Liu CL: Polymethylmethacrylate augmentation of cannulated pedicle screws for fixation in osteoporotic spines and comparison of its clinical results and biomechanical characteristics with the needle injection method. J Spinal Disord Tech 26:305-315, 2013

11. Chang MC, Liu CL, Chen TH: Polymethylmethacrylate augmentation of pedicle screw for osteoporotic spinal surgery: a novel technique. Spine (Phila Pa 1976) 33:E317-E324, 2008

12. Chen LH, Tai CL, Lai PL, Lee DM, Tsai TT, Fu TS, et al: Pullout strength for cannulated pedicle screws with bone cement augmentation in severely osteoporotic bone: influences of radial hole and pilot hole tapping. Clin Biomech (Bristol, Avon) 24:613-618, 2009

13. Chen YL, Chen WC, Chou CW, Chen JW, Chang CM, Lai YS, et al: Biomechanical study of expandable pedicle screw fixation in severe osteoporotic bone comparing with conventional and cement-augmented pedicle screws. Med Eng Phys 36:1416-1420, 2014

14. Chen Z, Zhao J, Xu H, Liu A, Yuan J, Wang C: Technical factors related to the incidence of adjacent superior segment facet joint violation after transpedicular instrumentation in the lumbar spine. Eur Spine J 17:1476-1480, 2008
15. Downie WW, Leatham PA, Rhind VM, Wright V, Branco JA, Anderson JA: Studies with pain rating scales. Ann Rheum Dis 37:378-381, 1978

16. Duran C, Sirvanci M, Aydoğan M, Ozturk E, Ozturk C, Akman C: Pulmonary cement embolism: a complication of percutaneous vertebroplasty. Acta Radiol 48:854-859, 2007

17. Fölsch C, Goost H, Figiel J, Paletta JR, Schultz W, Lakemeier $\mathrm{S}$ : Correlation of pull-out strength of cement-augmented pedicle screws with CT-volumetric measurement of cement. Biomed Tech (Berl) 57:473-480, 2012

18. Frankel BM, D'Agostino S, Wang C: A biomechanical cadaveric analysis of polymethylmethacrylate-augmented pedicle screw fixation. J Neurosurg Spine 7:47-53, 2007

19. Frankel BM, Jones T, Wang C: Segmental polymethylmethacrylate-augmented pedicle screw fixation in patients with bone softening caused by osteoporosis and metastatic tumor involvement: a clinical evaluation. Neurosurgery 61:531538,2007

20. Goost H, Deborre C, Wirtz DC, Burger C, Prescher A, Fölsch $\mathrm{C}$, et al: PMMA-augmentation of incompletely cannulated pedicle screws: a cadaver study to determine the benefits in the osteoporotic spine. Technol Health Care 22:607-615, 2014

21. Groen RJ, Groenewegen HJ, van Alphen HA, Hoogland PV: Morphology of the human internal vertebral venous plexus: a cadaver study after intravenous Araldite CY 221 injection. Anat Rec 249:285-294, 1997

22. Hierholzer J, Fuchs H, Westphalen K, Venz S, Pappert D, Depriester C: [Percutaneous vertebroplasty-the role of osseous phlebography.] Rofo 177:386-392, 2005 (Ger)

23. Hirano T, Hasegawa K, Takahashi HE, Uchiyama S, Hara T, Washio T, et al: Structural characteristics of the pedicle and its role in screw stability. Spine (Phila Pa 1976) 22:25042510,1997

24. Hiwatashi A, Westesson PL, Yoshiura T, Noguchi T, Togao $\mathrm{O}$, Yamashita K, et al: Kyphoplasty and vertebroplasty produce the same degree of height restoration. AJNR Am J Neuroradiol 30:669-673, 2009

25. Hu MH, Wu HT, Chang MC, Yu WK, Wang ST, Liu CL: Polymethylmethacrylate augmentation of the pedicle screw: the cement distribution in the vertebral body. Eur Spine J 20:1281-1288, 2011

26. Huber FX, McArthur N, Tanner M, Gritzbach B, Schoierer O, Rothfischer W, et al: Kyphoplasty for patients with multiple myeloma is a safe surgical procedure: results from a large patient cohort. Clin Lymphoma Myeloma 9:375-380, 2009

27. Kafchitsas K, Geiger F, Rauschmann M, Schmidt S: [Cement distribution in vertebroplasty pedicle screws with different designs.] Orthopade 39:679-686, 2010 (Ger)

28. Kasó G, Horváth Z, Szenohradszky K, Sándor J, Dóczi T: Comparison of CT characteristics of extravertebral cement leakages after vertebroplasty performed by different navigation and injection techniques. Acta Neurochir (Wien) 150:677-683, 2008

29. Kerry G, Ruedinger C, Steiner HH: Cement embolism into the venous system after pedicle screw fixation: case report, literature review, and prevention tips. Orthop Rev (Pavia) 5:e24, 2013

30. Kim YJ, Lee JW, Park KW, Yeom JS, Jeong HS, Park JM, et al: Pulmonary cement embolism after percutaneous vertebroplasty in osteoporotic vertebral compression fractures: incidence, characteristics, and risk factors. Radiology 251:250-259, 2009

31. Klingler JH, Scholz C, Kogias E, Sircar R, Krüger MT, Volz F, et al: Minimally invasive technique for PMMA augmentation of fenestrated screws. ScientificWorldJournal 2015:979186, 2015

32. Krauss M, Hirschfelder H, Tomandl B, Lichti G, Bär I: Kyphosis reduction and the rate of cement leaks after verte- 
broplasty of intravertebral clefts. Eur Radiol 16:1015-1021, 2006

33. Krueger A, Bliemel C, Zettl R, Ruchholtz S: Management of pulmonary cement embolism after percutaneous vertebroplasty and kyphoplasty: a systematic review of the literature. Eur Spine J 18:1257-1265, 2009

34. Liu D, Zhang Y, Zhang B, Xie QY, Wang CR, Liu JB, et al: Comparison of expansive pedicle screw and polymethylmethacrylate-augmented pedicle screw in osteoporotic sheep lumbar vertebrae: biomechanical and interfacial evaluations. PLoS One 8:e74827, 2013

35. Moon BJ, Cho BY, Choi EY, Zhang HY: Polymethylmethacrylate-augmented screw fixation for stabilization of the osteoporotic spine: a three-year follow-up of 37 patients. J Korean Neurosurg Soc 46:305-311, 2009

36. Pitton MB, Herber S, Koch U, Oberholzer K, Drees P, Düber C: CT-guided vertebroplasty: analysis of technical results, extraosseous cement leakages, and complications in 500 procedures. Eur Radiol 18:2568-2578, 2008

37. Popp AW, Schwyn R, Schiuma D, Keel MJ, Lippuner K, Benneker LM: DensiProbe Spine: an intraoperative measurement of bone quality in spinal instrumentation. A clinical feasibility study. Spine J 13:1223-1229, 2013

38. Rahamimov N, Mulla H, Shani A, Freiman S: Percutaneous augmented instrumentation of unstable thoracolumbar burst fractures. Eur Spine J 21:850-854, 2012

39. Röllinghoff M, Siewe J, Eysel P, Delank KS: Pulmonary cement embolism after augmentation of pedicle screws with bone cement. Acta Orthop Belg 76:269-273, 2010

40. Roy-Camille R, Saillant G, Mazel C: Internal fixation of the lumbar spine with pedicle screw plating. Clin Orthop Relat $\operatorname{Res}(\mathbf{2 0 3})$ :7-17, 1986

41. Schmidt R, Cakir B, Mattes T, Wegener M, Puhl W, Richter M: Cement leakage during vertebroplasty: an underestimated problem? Eur Spine J 14:466-473, 2005

42. Shea TM, Laun J, Gonzalez-Blohm SA, Doulgeris JJ, Lee WE III, Aghayev K, et al: Designs and techniques that improve the pullout strength of pedicle screws in osteoporotic vertebrae: current status. BioMed Res Int 2014:748393, 2014

43. Soshi S, Shiba R, Kondo H, Murota K: An experimental study on transpedicular screw fixation in relation to osteoporosis of the lumbar spine. Spine (Phila Pa 1976) 16:13351341,1991

44. Tanigawa N, Kariya S, Komemushi A, Tokuda T, Nakatani $\mathrm{M}$, Yagi R, et al: Cement leakage in percutaneous vertebroplasty for osteoporotic compression fractures with or without intravertebral clefts. AJR Am J Roentgenol 193:W442W445, 2009

45. Venmans A, Klazen CA, van Rooij WJ, de Vries J, Mali WP, Lohle PN: Postprocedural CT for perivertebral cement leakage in percutaneous vertebroplasty is not necessary-results from VERTOS II. Neuroradiology 53:19-22, 2011

46. Venmans A, Lohle PN, van Rooij WJ, Verhaar HJ, Mali WP: Frequency and outcome of pulmonary polymethylmethacrylate embolism during percutaneous vertebroplasty. AJNR Am J Neuroradiol 29:1983-1985, 2008

47. Voggenreiter G, Brocker K, Röhrl B, Sadick M, Obertacke $\mathrm{U}$ : [Results of balloon kyphoplasty in the treatment of os- teoporotic vertebral compression fractures.] Unfallchirurg 111:403-412, 2008 (Ger)

48. Vogl TJ, Proschek D, Schwarz W, Mack M, Hochmuth K: CT-guided percutaneous vertebroplasty in the therapy of vertebral compression fractures. Eur Radiol 16:797-803, 2006

49. Weber CH, Krötz M, Hoffmann RT, Euler E, Heining S, Pfeifer KJ, et al: [CT-guided vertebroplasty and kyphoplasty: comparing technical success rate and complications in 101 cases.] Rofo 178:610-617, 2006 (Ger)

50. Wegmann K, Gick S, Heidemann C, Pennig D, Neiss WF, Müller LP, et al: Biomechanical evaluation of the primary stability of pedicle screws after augmentation with an innovative bone stabilizing system. Arch Orthop Trauma Surg 133:1493-1499, 2013

51. Weinstein JN, Rydevik BL, Rauschning W: Anatomic and technical considerations of pedicle screw fixation. Clin Orthop Relat Res (284):34-46, 1992

52. Weinstein JN, Spratt KF, Spengler D, Brick C, Reid S: Spinal pedicle fixation: reliability and validity of roentgenogrambased assessment and surgical factors on successful screw placement. Spine (Phila Pa 1976) 13:1012-1018, 1988

53. Wu ZX, Gao MX, Sang HX, Ma ZS, Cui G, Zhang Y, et al: Surgical treatment of osteoporotic thoracolumbar compressive fractures with open vertebral cement augmentation of expandable pedicle screw fixation: a biomechanical study and a 2-year follow-up of 20 patients. J Surg Res 173:91-98, 2012

54. Yeom JS, Kim WJ, Choy WS, Lee CK, Chang BS, Kang JW: Leakage of cement in percutaneous transpedicular vertebroplasty for painful osteoporotic compression fractures. J Bone Joint Surg Br 85:83-89, 2003

55. Zindrick MR, Wiltse LL, Widell EH, Thomas JC, Holland WR, Field BT, et al: A biomechanical study of intrapeduncular screw fixation in the lumbosacral spine. Clin Orthop Relat Res (203):99-112, 1986

\section{Disclosures}

Jan U. Mueller is a consultant to Signus Medizintechnik GmbH and Ulrich $\mathrm{GmbH}$.

\section{Author Contributions}

Conception and design: Mueller, Baldauf, Pillich. Acquisition of data: Mueller, Kirsch, Pillich. Analysis and interpretation of data: Marx, Mueller, Baldauf, Kirsch, Pillich. Drafting the article: Marx, Pillich. Critically revising the article: Marx, Mueller, Baldauf, Schroeder. Reviewed submitted version of manuscript: Marx, Schroeder. Approved the final version of the manuscript on behalf of all authors: Marx. Study supervision: Mueller, Baldauf, Schroeder.

\section{Correspondence}

Sascha Marx, Department of Neurosurgery, University of Greifswald, Sauerbruchstraße, Greifswald 17475, Germany. email: marxs@uni-greifswald.de. 